\title{
miR-27 inhibits the NF-kB signaling pathway by targeting leptin in osteoarthritic chondrocytes
}

\author{
BIN ZHOU*, HONGWEI LI* and JIDE SHI \\ Department of Orthopaedics, The Second Hospital of Lanzhou University, Lanzhou, Gansu 730000, P.R. China
}

Received February 27, 2016; Accepted January 31, 2017

DOI: 10.3892/ijmm.2017.3021

\begin{abstract}
Osteoarthritis (OA) is a chronic degenerative joint disease. An increasing number of studies point to the role of microRNAs (miRNAs or miRs) in the pathogenesis of OA. An earlier study suggested that miR-27b was associated with $\mathrm{OA}$; however, the precise mechanisms regarding the involvement of the miR-27 in the progression of OA remain unclear. In the present study, we first analyzed the effects of miR-27 on OA. In vitro, the degree of miR-27 expression was decreased in chondrocytes obtained from patients with OA. Transfection with miR-27 mimic increased the viability of $\mathrm{CH} 8$ cells and induced the expression of type-II collagen, type-X collagen, glycosaminoglycan (GAG) and aggrecan (ACAN). The results of luciferase activity assay revealed that miR-27 directly targeted the 3'-untranslated region (3'-UTR) of leptin. The results of western blot analysis and ELISA indicated that the concentration of leptin was decreased after the $\mathrm{CH} 8$ cells were transfected with miR-27 mimic. In vivo, a rat model of OA was established by anterior cruciate ligament transection (ACLT). When the rats with OA were injected with miR-27 lentiviral overexpression vector, the results of ELISA revealed that the levels of interleukin (IL)- 6 and IL- 8 were decreased. The results of western blot analysis revealed that matrix metalloproteinase (MMP)-9 and MMP-13 expression levels were decreased, and the nuclear factor $-\kappa \mathrm{B}(\mathrm{NF}-\kappa \mathrm{B})$ pathway was inhibited. On the whole, our results suggest that the upregulation of miR-27 inhibits the pathogenesis of OA by targeting leptin and inhibiting the $\mathrm{NF}-\kappa \mathrm{B}$ signaling pathway. Thus, miR-27 exerts protective effects against OA.
\end{abstract}

Correspondence to: Dr Bin Zhou, Department of Orthopaedics, The Second Hospital of Lanzhou University, 82 Cuiyingmen Road, Chengguan, Lanzhou, Gansu 730000, P.R. China

E-mail: binzhoulanzhou@163.com

*Contributed equally

Key words: microRNA-27, leptin, osteoarthritic chondrocytes, nuclear factor- $\kappa \mathrm{B}$ pathway

\section{Introduction}

Osteoarthritis (OA) is a chronic degenerative joint disorder that causes pain, tenderness and limitation of movement (1). $\mathrm{OA}$ is a disease affecting the articular cartilage, in which the molecular biological characteristics are an aberrant expression of the genes involved in the synthesis and degradation of cartilage (2). The pathogenesis of OA is suspected to involve several risk factors, including age, obesity, prior joint injury, gender and genetic predisposition (3). Inflammation is a characteristic feature of OA. Inflammatory mediators, such as cytokines [interleukin (IL)-6 and tumor necrosis factor- $\alpha$ (TNF- $\alpha$ )], lipid derivatives (leptin, adiponectin and visfatin) and reactive oxygen species can be produced and activate the cells of the joint tissues (4).

The nuclear factor $-\kappa \mathrm{B}(\mathrm{NF}-\kappa \mathrm{B})$ proteins belong to a family of ubiquitously expressed transcription factors that play a significant role in most inflammatory responses (5). The NF- $\kappa$ B family includes 5 members: RelA (p65), RelB, $c-$ Rel, NF- $\kappa$ B1 and NF- $\kappa$ B2. Earlier studies have revealed that $N F-\kappa B$ is associated with the pathogenesis of OA. The NF- $\kappa B$ pathway acts as the central regulator of catabolic actions, mediating the crucial events in the inflammatory responses of chondrocytes, and leading to extracellular matrix damage and cartilage erosion (6). For example, the adenovirus-mediated delivery of p65 siRNA to rats with OA has been shown to attenuate cartilage destruction (7). p65 activates human SRY-box 9 (SOX9) promoter activity in chondrogenic cells (8). Therefore, NF- $\mathrm{BB}$ signaling plays a vital role both in the proinflammatory stress-related responses of chondrocytes and in the control of their differentiation program.

Leptin is an ubiquitous 16-kDa pleiotropic protein produced predominantly in white adipose tissue (9). Leptin is involved in various physiological processes, such as immune responses, inflammatory diseases, cardiovascular functions and respiratory pathophysiology $(10,11)$. Leptin is regarded as the new regulator of bone growth via the induction of collagen synthesis and the proliferation of osteoblasts (12). Leptin and the leptin receptor $\mathrm{Ob}-\mathrm{R}$ are produced by articular cartilage and the expression of these two factors is upregulated through $\mathrm{NF}-\kappa \mathrm{B}$ activation in patients with OA (13). Previous studies have demonstrated that the overexpression of leptin is directly associated with the degree of OA $(14,15)$.

MicroRNAs (miRNAs or miRs) are a group of small (approximately 22 nucleotides in length), non-coding RNAs 
and are regarded as crucial post-transcriptional gene regulators (16). Studies have demonstrated that miRNAs are involved in the progression of OA. miR-222 has been shown to control OA pathogenesis by targeting histone deacetylase-4 (17). The reduced functions of miR-370 and miR-373 have also been shown to result in the promotion of cell apoptosis in OA-affected chondrocytes (18). miR-27 has previously been reported to be decreased in OA-affected chondrocytes (1). The software predicated that miR-27 could target the 3'UTR of leptin. However, whether miR-27 plays an important role in the progression of OA by regulating leptin and the underlying mechanisms have not yet been determined. Thus, the aim of this study was to evaluate the exact effects of miR-27 and leptin in the progression of $\mathrm{OA}$ and to explore the underlying mechanisms.

\section{Materials and methods}

Cell culture. The CH8 cells were purchased from Shanghai Bioleaf Biotech Co., Ltd. (Shanghai, China). The cells were cultured in Dulbecco's modified Eagle's medium/Nutrient F-12 Ham (DMEM/F12) with 10\% fetal bovine serum (FBS) (both from Sigma Chemical Co., St. Louis, MO, USA) in a humidified incubator with an atmosphere of $95 \%$ air- $5 \% \mathrm{CO}_{2}$ at $37^{\circ} \mathrm{C}$. For in vitro experiments, the $\mathrm{CH} 8$ cells were exposed to IL-1 $\beta$ (the final concentration was $10 \mu \mathrm{g} / \mathrm{l}$ ), and untreated CH8 cells were considered as the control group. Human articular cartilage was obtained from patients with OA following total knee replacement surgery. Twenty cartilage tissues from patients with OA and 20 normol control tissues were collected. The chondrocytes were extracted according to a previously described method (19). Briefly, after surgical removal, the tissues were collected, and were frozen in liquid nitrogen, and stored at $-80^{\circ} \mathrm{C}$. The chondrocytes were minced and digested in $0.15 \%$ (w/v) collagenase in DMEM containing 10\% FBS, $100 \mathrm{U} / \mathrm{ml}$ penicillin and $100 \mu \mathrm{g} / \mathrm{ml}$ streptomycin (Sigma Chemical Co.) for $16 \mathrm{~h}$ at $37^{\circ} \mathrm{C}$. Primary OA chondrocytes used in the experiments were at $80 \%$ confluence.

RNA extraction and real-time PCR. Total RNA was extracted from the cells and tissues using TRIzol reagent (Invitrogen, Carlsbad, CA, USA). First Strand cDNA was synthesized using the MMLV Reverse Transcriptase kit (Takara, Dalian, China). Real-time PCR was performed using the SYBR Premix Ex Taq ${ }^{\mathrm{TM}}$ kit (Takara). All the primers used in this study were synthesized by Sangon Biotech (Shanghai, China). Each individual sample was run in triplicate wells and conducted in the ABI 7500 Real-time PCR system (Applied Biosystems, Carlsbad, CA, USA). The reactions were initially denatured at $95^{\circ} \mathrm{C}$ for $30 \mathrm{sec}$ followed by 40 cycles at $95^{\circ} \mathrm{C}$ for $10 \mathrm{sec}$ and $60^{\circ} \mathrm{C}$ for $60 \mathrm{sec}$. The relative degrees of expression of the genes tested were calculated using the $2^{-\Delta \Delta \mathrm{Cq}}$ method. 18 s RNA was selected as the reference gene.

Isolation and culture of primary rat chondrocytes. All the animal experiment protocols were approved by the Institutional Animal Care and Use Committee of the Second Hospital of Lanzhou University, Lanzhou, China. After experimentation, the mice were euthanized. Sprague-Dawley rats (8 weeks, 210-250 g) were purchased from Better Biotec hnology Co., Ltd. (Nangjing, China). A rat model of OA was established by subjecting the rats to anterior cruciate ligament transection (ACLT) in the right knees. A total of 60 rats were randomly divided into 6 groups as follows: the normal control group ( $\mathrm{NC}, \mathrm{n}=10$ ), the OA model group (OA, $\mathrm{n}=10$ ), the OA model injected with miR-27 lentivirus overexpression vector $(\mathrm{OA}+$ pre-lenti-miR-27, $\mathrm{n}=10)$, the $\mathrm{OA}$ model injected with lentivirus overexpression vector control $(\mathrm{OA}+$ pre-lenticontrol, $n=10)$, the OA model injected with lentivirus inhibitor vector (OA + inhibitor-lenti-miR-27, $n=10)$, the OA model injected with miR-27 lentivirus inhibitor vector control (OA + inhibitor-lenti-control, $n=10)$. The rats in each group were euthanized on the 14th day after the injection of miR-27 lentivirus vector. Primary rat chondrocytes were isolated as previously described (20). Brefily, articular cartilages were removed under sterile conditions. The slices were then cultured in DMEM/F12 (containing 10\% FCS, $100 \mu \mathrm{g} / \mathrm{ml}$ streptomycin, $100 \mathrm{U} / \mathrm{ml}$ penicillin) after being cut into small sections. The cells were then maintained at $37^{\circ} \mathrm{C}$ for $24 \mathrm{~h}$. The undigested cartilage was removed and the chondrocyte cells were centrifuged at $2,000 \mathrm{xg}$ for $5 \mathrm{~min}$. The supernatants were collected for testing by western blot analysis and enzymelinked immunosorbent assay (ELISA).

Transfection. The CH8 cells were transfected with $80 \mu \mathrm{M}$ of the miR-27 mimic, miR-27 inhibitor and corresponding control using Lipofectamine 2000 reagent (Invitrogen). After $48 \mathrm{~h}$, the cells were harvested for RNA isolation and western blot analysis.

Western blot analysis. The chondrocytes were extracted using protein lysis buffer supplemented with a protease inhibitor cocktail. The chondrocytes were then placed on ice for $30 \mathrm{~min}$ and the cells were then centrifuged at $12,000 \mathrm{x} \mathrm{g}$ for $10 \mathrm{~min}$. The total proteins $(30 \mathrm{mg})$ were electrophoresed and transferred onto polyvinylidene difluoride (PVDF) membranes (Millipore, Darmstadt, Germany). The membranes were then probed with primary antibodies specific for type-II collagen (1:5,000 dilution; Cat. no. ab34712; Abcam, Cambridge, UK), type-X collagen (1:300 dilution; Cat. no. ab58632), glycosaminoglycan (GAG) (1:1,500 dilution; Cat. no. ab100970) and aggrecan (ACAN) (1:100 dilution; Cat. no. ab3778), matrix metalloproteinase (MMP)-9 (1:1,000 dilution; Cat. no. ab73734), MMP-13 (1:3,000 dilution; Cat. no. ab39012); p65 (sc-8008) and p-IкB $\alpha$ (sc-52943) (1:1,000 dilution; Santa Cruz Biotechnology, Santa Cruz, CA). Following incubation at $4^{\circ} \mathrm{C}$ overnight, the appropriate HRP-conjugated secondary antibody (1:2,000 dilution; Cat. no. ab6721, Abcam) was added for $1 \mathrm{~h}$ of incubation at room temperature. The immunoreactive proteins were visualized using an ECL system (Amersham Biosciences, Amersham, UK).

MTT assay. After the CH8 cells $\left(4 \times 10^{4}\right.$ cells/well) were cultured overnight, the cells were transfected with the miR-27 mimic, miR-27 inhibitor and corresponding controls for 24, 48 and $72 \mathrm{~h}$ using Lipofectamine. Subsequently, $20 \mu \mathrm{l}$ of 3-(4,5-dimethylthiazol-2-yl)-2,5-diphenyltetrazolium bromide (MTT) was added for a further $4 \mathrm{~h}$ of incubation. The blue formazan crystals of viable cells were solubilized in $150 \mu$ l dimethyl sulfoxide (DMSO). The absorbance was 

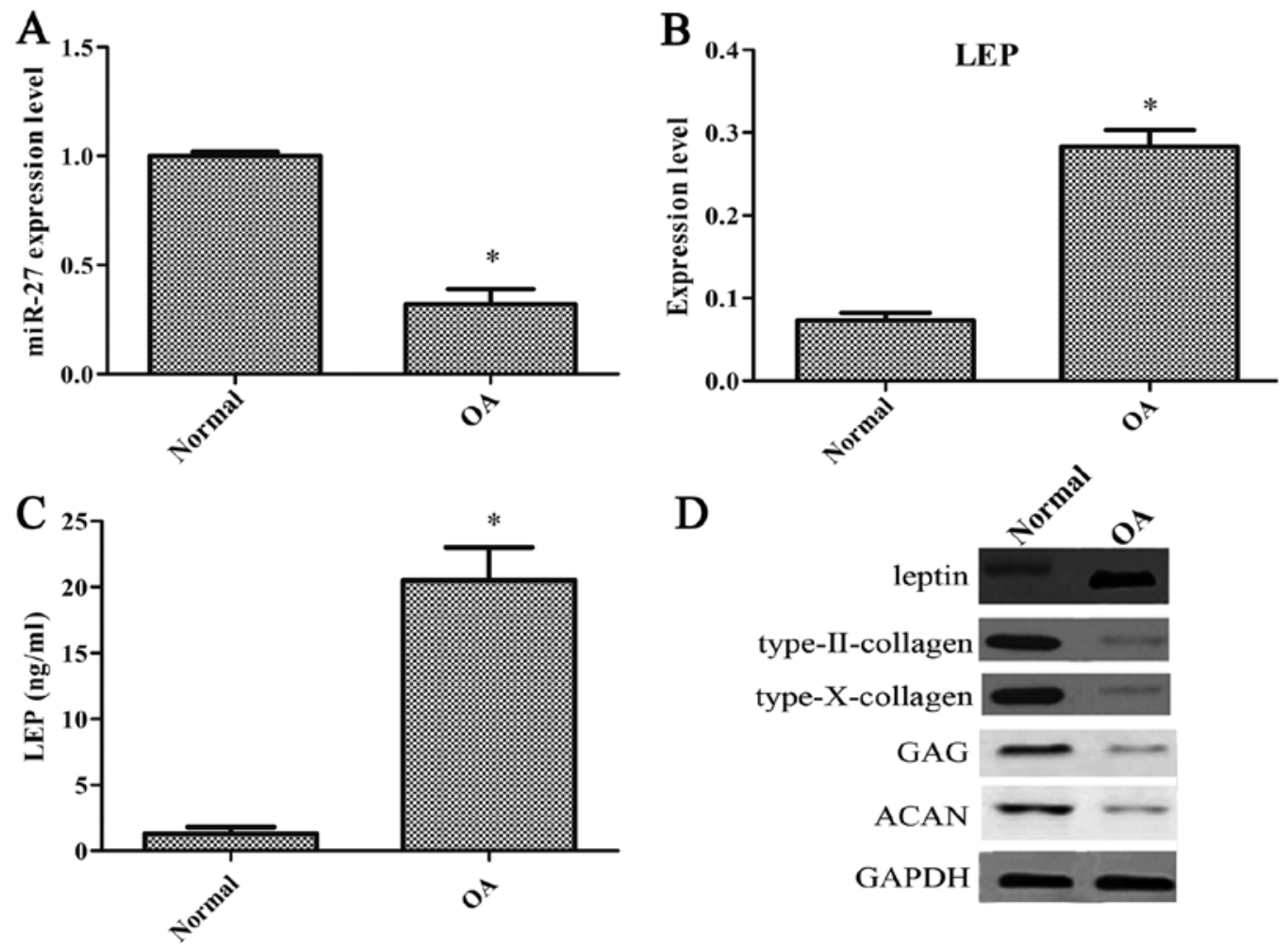

D

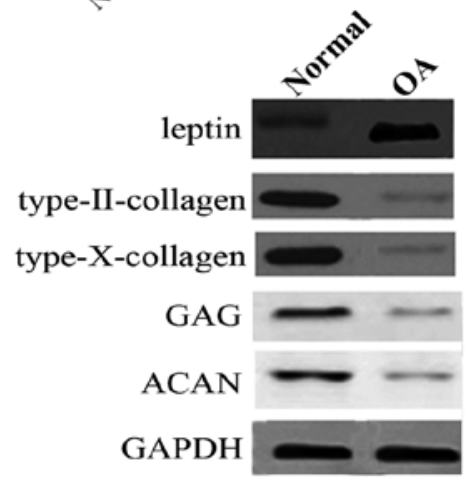

Figure 1. miR-27 expression is decreased and that of leptin is increased in human osteoarthritic chondrocytes. Human articular cartilage was obtained from the total knee replacements of patients with osteoarthritis (OA). Twenty cartilage tissues of patients with OA and 20 normal controls were collected. (A) The miR-27 mRNA level in chondrocytes of patients with OA was measured by real-time PCR. (B) The mRNA expression level of leptin (LEP) in chondrocytes from patients with OA. (C) The leptin concentration in chondrocytes from patients with OA was detected by enzyme-linked immunosorbent assay (ELISA). (D) The expression levels of leptin and chondrogenesis-related markers were measured by western blot analysis. ${ }^{*} \mathrm{P}<0.05$ compared to normal controls.

measured at $490 \mathrm{~nm}$ using a microplate reader. The experiments were repeated 3 times.

Bioinformatics analysis. TargetScanHuman7.0 software was used to predict the target gene of miR-27 (http://www. targetscan.org/vert_71/).

Luciferase reporter assay. The $\mathrm{CH} 8$ cells were transfected with $0.25 \mu \mathrm{g}$ of the p-MiR-report plasmid (Ambion, Austin, TX, USA) containing the 3'-untranslated region (3'-UTR) of leptin. A mutated 3'-UTR of leptin was introduced into the potential miR-27 binding site using the Nested PCR method. The missing sites of the mutant were from 700 to 725 . The $\mathrm{CH} 8$ cells were then transfected with the reporter vectors containing the wild-type or mutant of leptin 3'-UTR and miR-27 mimic, inhibitor and corresponding controls. Luciferase activity was measured using a dual-luciferase reporter assay system (Promega, Madison, WI, USA) following $48 \mathrm{~h}$ of transfection.

ELISA. The culture supernatants were used to detect the levels of IL-6, IL- 8 and leptin. The levels of IL-6 and IL-8 were measured using IL-6, IL-8 specific ELISA kits (Sigma Chemical Co.) according to the manufacturer's instructions. Leptin was measured using the human leptin ELISA kit (Sigma Chemical Co.).

Statistical analysis. Statistical analysis was performed using the Student's unpaired t-test (SPSS release 19.0; SPSS, Inc., Chicago, IL, USA). Data are expressed as the means \pm SD.

\section{Results}

miR-27 expression is decreased and that of leptin is increased in chondrocytes from patients with $O A$. To examine the effects of miR-27 and leptin on the progression of OA, we initially measured the degrees of miR-27 and leptin expression in the human articular cartilage from patients with OA and normal healthy patients. The degree of miR-27 expression was significantly decreased in the OA-affected chondrocytes compared with the normal chondrocytes (Fig. 1A). The degree of leptin expression was notably increased in the OA-affected chondrocytes (Fig. 1B). Compared with the normal chondrocytes, the concentration of leptin was significantly increased in the OA-affected chondrocytes (Fig. 1C). The levels of type-II collagen, type-X collagen, GAG and ACAN were also decreased in the OA-affected chondrocytes (Fig. 1D).

miR-27 enhances the viability of the CH8 cells and induces chondrogenesis. As miR-27 expression was markedly decreased in OA-affected chondrocytes, we thus considered it possible that miR-27 may act as an inhibitor of OA. Therefore, we further investigated the effects of miR-27 on cell viability. The $\mathrm{CH} 8$ cells that were exposed to IL-1 $\beta$ were transfected with miR-27 mimic, miR-27 inhibitor and their corresponding controls. The transfection efficiency was very high compared with the corresponding controls (Fig. 2A). As shown in Fig. 2B, cell viability in the group transfected with the miR-27 mimic was markedly increased, while it was significantly decreased in the group transfected with the miR-27 inhibitor. In order to determine whether miR-27 

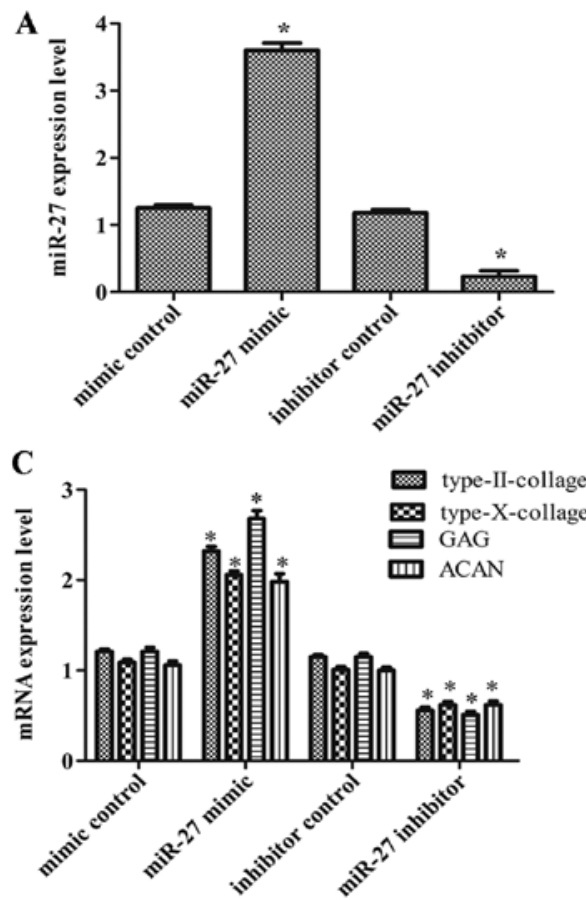

$\mathbf{E}$

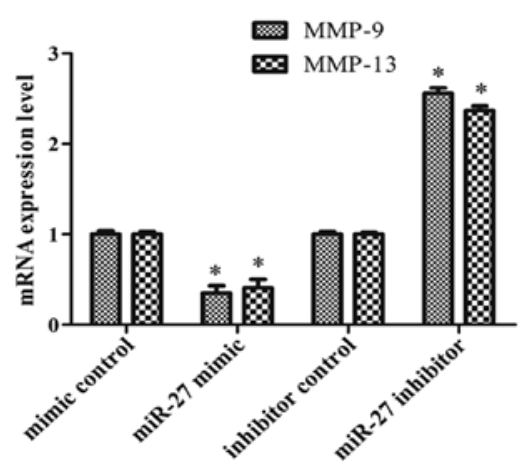

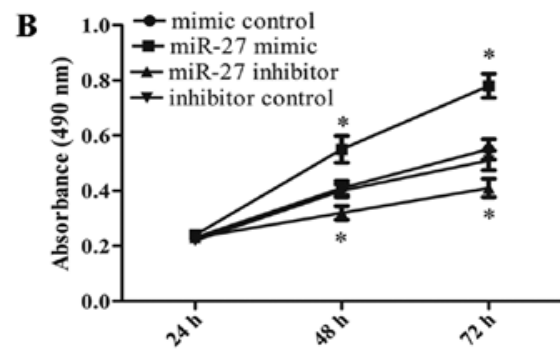

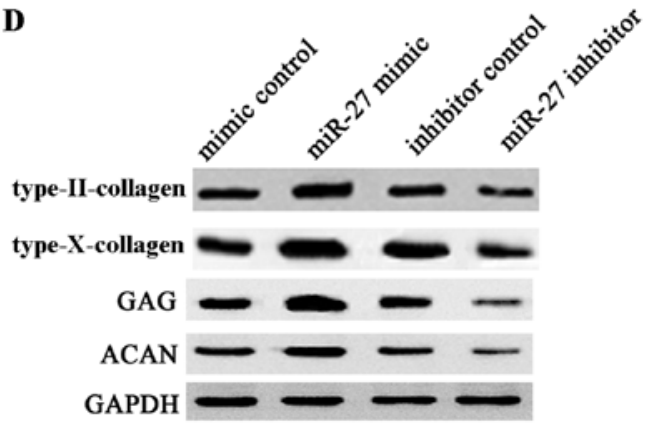

F
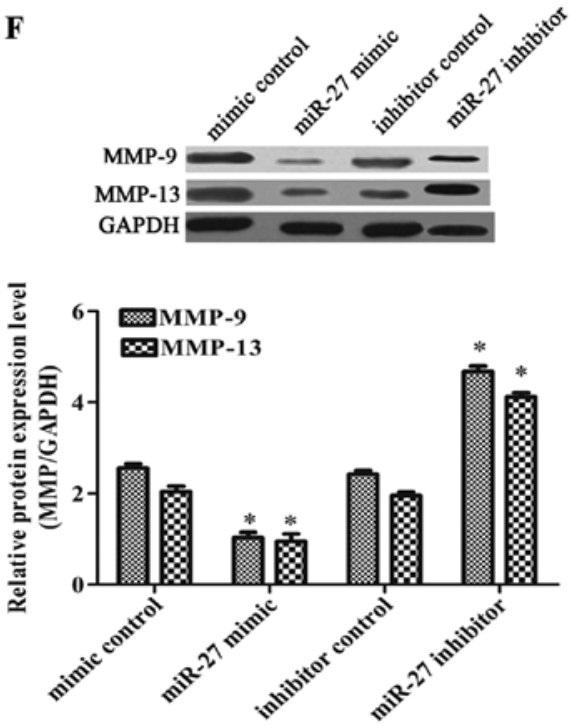

Figure 2. miR-27 increases the viability of CH8 cells and induces chondrogenesis. (A) Expression of miR-27 in CH8 cells that were exposed to IL-1 $\beta$ and were transfected with the miR-27 mimic, inhibitor or corresponding control measured by real-time PCR. (B) After the IL-1 $\beta$-exposed cells were transfected with the miR-27 mimic, inhibitor or corresponding control for 24,48 and $72 \mathrm{~h}$, cell viability was detected by MTT assay. (C) mRNA expression of chondrogenesis-related markers measured by real-time PCR. (D) The protein levels of expression of the chondrogenesis-related markers were measured by western blot analysis. (E) The mRNA levels of the matrix metalloproteinase (MMP)-9 and MMP-13 expression were measured by real-time PCR. (F) The protein expression levels of MMP-9 and MMP-13 were measured by western blot analysis. " $\mathrm{P}<0.05$ compared to controls.

plays a positive role in chondrogenesis, we also investigated the expression levels of type-II collagen, type-X collagen, ACAN and GAG. As shown in Fig. 2C and D, we found that infection with the miR-27 mimic induced an increase in the expression of type-II collagen, type-X collagen, GAG and ACAN; however, infection with the miR-27 inhibitor led to a marked decrease in these expression levels. In addition, transfection with miR-21 mimic markedly decreased the degrees of MMP-9 and MMP-13 expression, whereas these expression levels were increased in the group of the miR-27 inhibitor (Fig. 2E and F). On the whole, our data demonstrated that miR-27 increased the viability of the $\mathrm{CH} 8$ cells and induced chondrogenesis.
miR-27 directly targets leptin. The results of the analysis using TargetScan Human 7.0 revealed that leptin may be the target of miR-27 (Fig. 3A). The results of real-time PCR and western blot analysis revealed that leptin expression was significantly increased in the IL- $1 \beta$-exposed $\mathrm{CH} 8$ cells compared with the control cells (Fig. 3B and D). This result was consistent with leptin expression in human OA chondrocytes. As shown in Fig. 3D, we found that miR-27 expression inversely correlated with leptin expression. The relative luciferase activity was markedly decreased when the cells were transfected with the wild-type leptin 3'-UTR and miR-27 mimic, and significantly increased when the cells were transfected with the wild-type 
A

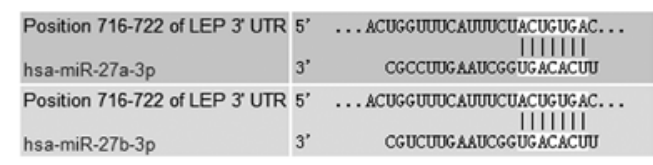

C

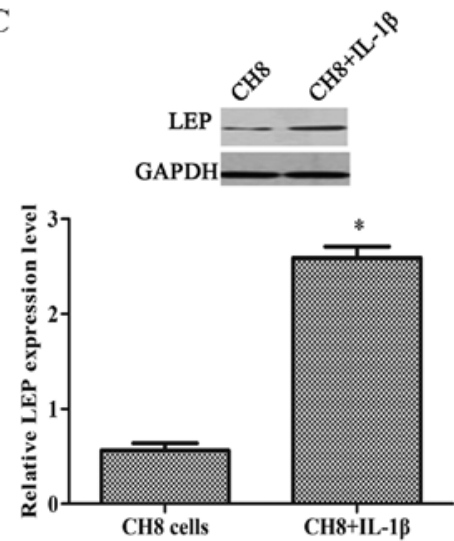

$\mathbf{E}$

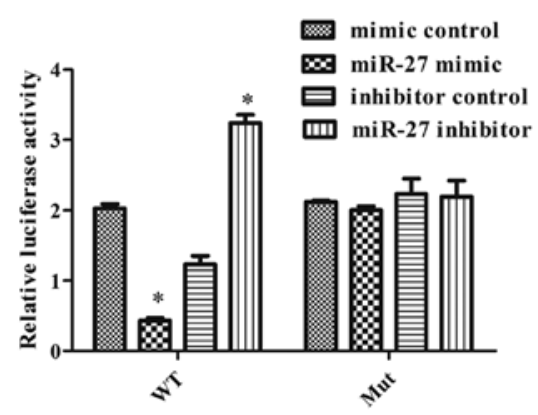

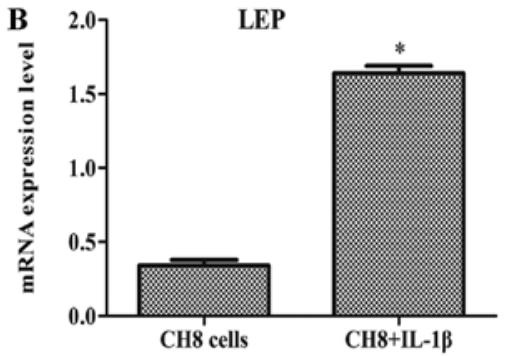

D
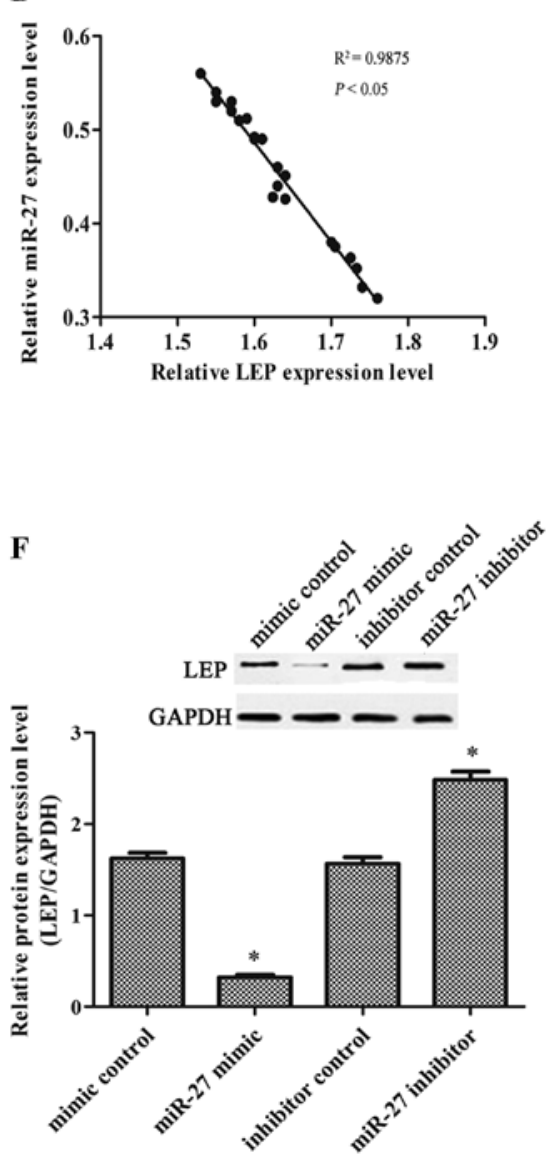

Figure 3. (A) miR-27 directly targets leptin. The prediction result of miR-27 targeted the 3'-UTR of leptin through TargetScan Human 7.0 Software. (B) mRNA expression of leptin in the IL- $1 \beta$-exposed CH8 cells was measured by real-time PCR. (C) Protein expression of leptin in the the IL-1 $\beta$-exposed CH8 cells was measured by western blot analysis. (D) The expression of miR-27 inversely correlated with leptin expression. (E) Relative luciferase activity of CH8 cells which were co-transfected with the miR-27 mimic, inhibitor or corresponding control plus a leptin 3'-UTR fragment containing either the miR-27 target sequence (WT) or a mutant(Mut) sequence. (F) After the CH8 cells were exposed to IL-1 $\beta$ and were transfected with miR-27 mimic, miR-27 inhibitor and corresponding controls, the expression of leptin was measured. ${ }^{*} \mathrm{P}<0.05$ compared to controls.

leptin 3'-UTR and miR-27 inhibitor (Fig. 3E). The results indicated that leptin was the direct target of miR-27. The results of western blot analysis also confirmed that when the IL-1 $\beta$ exposed cells were transfected with the miR-27 mimic, the level of leptin expression was markedly decreased. When the IL-1 $\beta$-exposed cells were transfected with the miR-27 inhibitor, leptin expression was markedly increased (Fig. 3F). These results indicated that miR-27 suppressed leptin expression posttranscriptionally.

miR-27 increases the immunomodulatory activity and inhibits the activation of the $N F-\kappa B$ pathway in a rat model of $O A$. To examine the effect of miR-27 in vivo, a rat model of OA was established by performing ACLT on the right knees of the rats. The rats with $\mathrm{OA}$ were injected with the overexpression or inhibitor vectors of the miR-27 lentivirus and their corresponding controls. As shown in Fig. 4A, the expression level of miR-27 in the articular cartilage was significantly decreased in the rats with OA. The levels of IL- 6 and IL- 8 were markedly decreased when the rats with OA were injected with the miR-27 lentivirus overexpression vector. However, the levels of IL-6 and IL- 8 were markedly increased when the rats with OA were injected with the miR-27 lentivirus inhibitor vector (Fig. 4B). In addition, the expression levels of MMP-9 and MMP-13 were notably decreased when the rats with OA were injected with the miR-27 lentivirus overexpression vector, and they were significantly increased when the rats with $\mathrm{OA}$ were injected with the miR-27 lentivirus inhibitor vector (Fig. 4C). The expression of $\mathrm{p}$-I $\kappa \mathrm{B} \alpha$ was decreased 2.98-fold compared with the control when the rats with OA were injected with the miR-27 
A

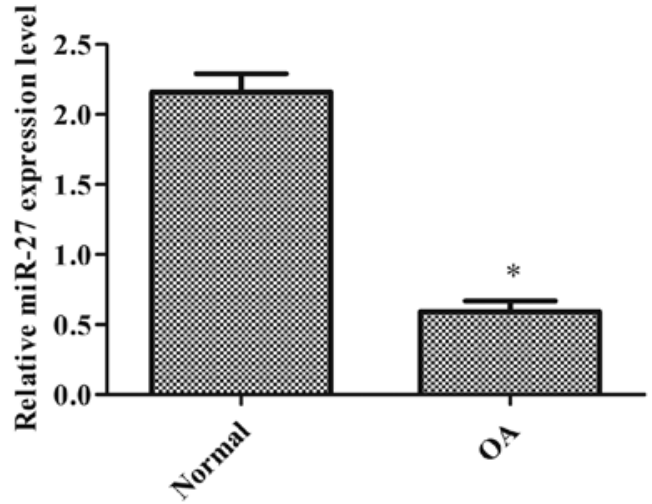

$\mathrm{C}$

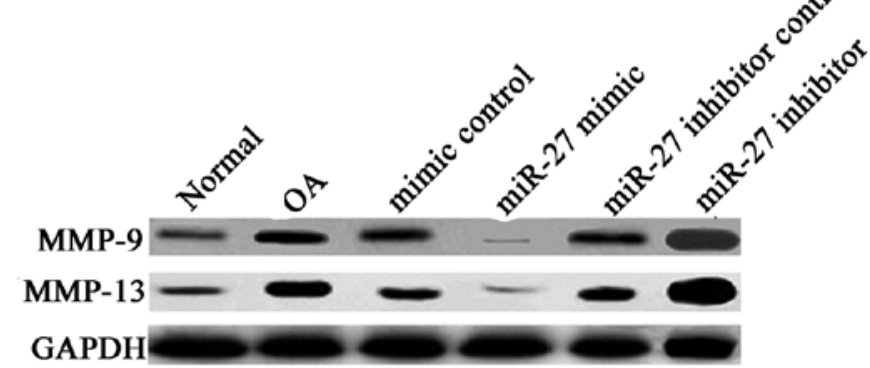

D

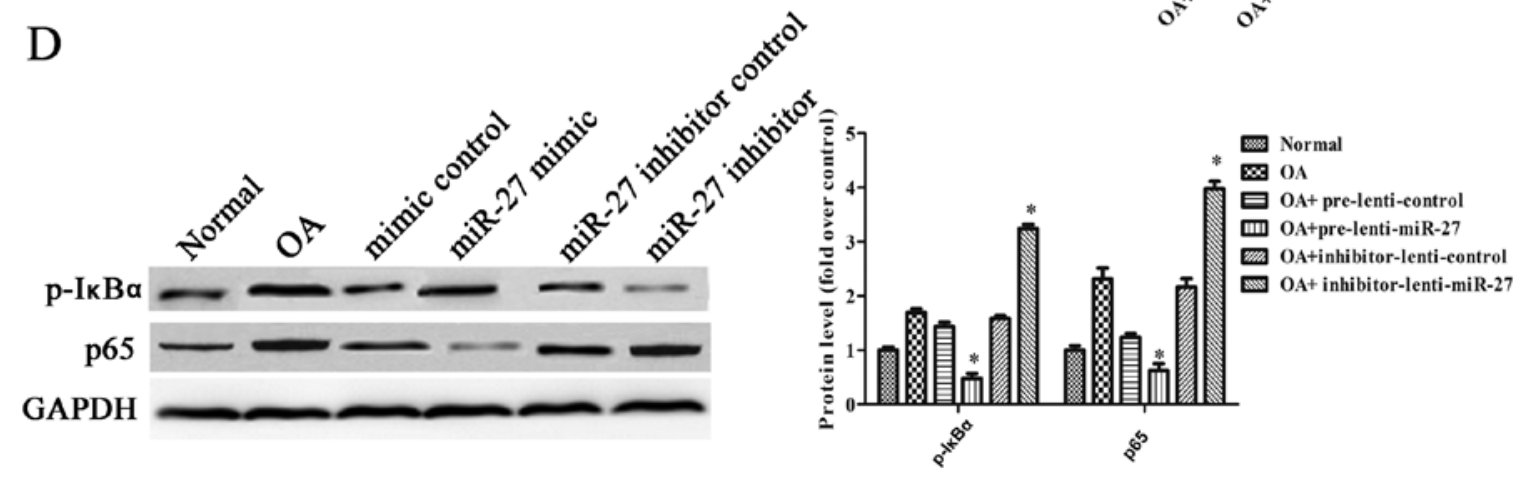

Figure 4. miR-27 increases the immunomodulatory activity and inhibits the NF- $\mathrm{B}$ pathway in a rat model of osteoarthritis (OA). (A) The expression of miR-27 in rats with OA. (B) After the rats with OA were injected with miR-27 lentivirus overexpression vector, inhibitor or corresponding controls, the concentrations of interleukin-6 (IL)-6 and IL-8 were measured by enzyme-linked immunosorbent assay (ELISA). (C) The protein expression levels of the matrix metalloproteinase (MMP)-9 and MMP-13 were measured by western blot analysis. (D) The protein expression of p-IкB $\alpha$ and p65 were measured by western blot analysis. ${ }^{*} \mathrm{P}<0.05$ compared to controls.

lentivirus overexpression vector, and was increased 2.05-fold when the rats with OA were injected with the miR-27 lentivirus inhibitor vector. The expression of p65 was decreased 2.00-fold compared when the rats with OA were injected with the miR-27 lentivirus vector overexpression, and increased 1.84-fold when the rats with OA were injected with the miR-27 lentivirus inhibitor vector (Fig. 4D). These results suggested that miR-27 increased the immunomodulatory activity and inhibited the $\mathrm{NF}-\kappa \mathrm{B}$ pathway in the rats with OA.

\section{Discussion}

A previous study confirmed that miR-27 was downregulated in human OA-affected chondrocytes (1). In this study, we also verified that miR-27 expression was decreased both in vivo and in vitro. Leptin was predicted to be a target of miR-27. Leptin
B
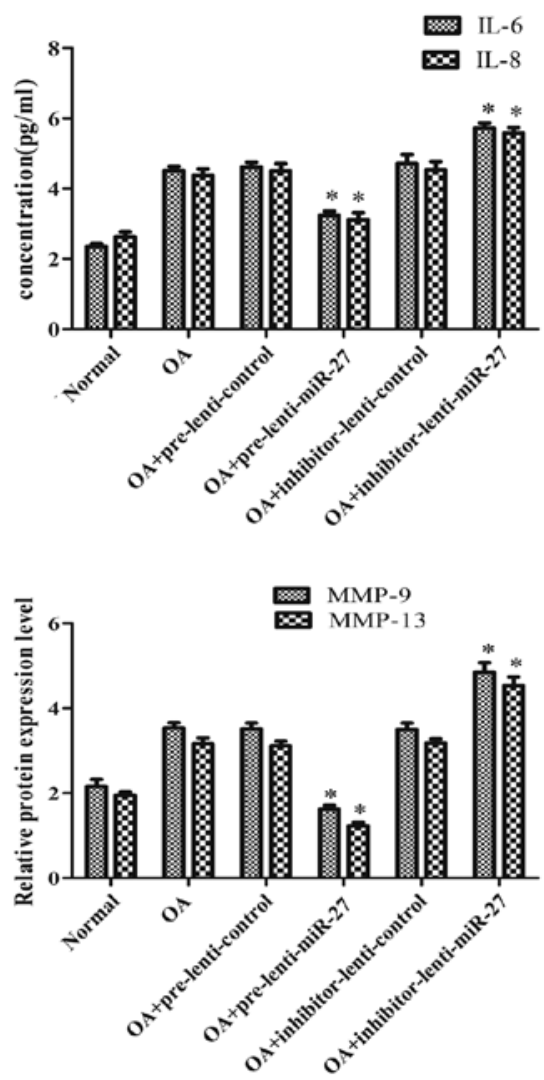
the miR-27 mimic. However, when the cells were transfected with the miR-27 inhibitor, $\mathrm{CH} 8$ cell proliferation was markedly decreased. Furthermore, the degrees of chondrogenesis-related protein expression displayed similar effects. The levels of type-II collagen, type-X collagen, GAG and ACAN were all increased in response to $\mathrm{miR}-27$ overexpression. Therefore, it was suggested that miR-27 increased the viability of $\mathrm{CH} 8$ cells and induced chondrogenesis.

We further confirmed that miR-27 played protective a role in OA by targeting leptin. The results demonstrated that leptin was upregulated in the OA-affected chondrocytes. The results of luciferase activity assay indicated that leptin was the direct target of miR-27. The results of western blot analysis also indicated that miR-27 mimic suppressed leptin expression. Over the years, leptin has been recognized as a cytokine-like factor with pleiotropic actions both in the immune response and inflammation $(25,26)$. For instance, leptin has been shown to promote MMP-1 and MMP-3 production in human OA cartilage (27). Leptin also induces the proliferation of osteoarthritis-related subchondral osteoblasts (28). Moreover, low leptin levels promote chondrocyte proliferation and proteoglycan synthesis, and correspondingly the overproduction of leptin-induced nitric oxide synthase, which accelerates cartilage degradation (29). Therefore, it was suggested that miR-27 acts as an inhibitor of OA through the downregulation of leptin expression.

Earlier studies have confirmed that leptin activates the $\mathrm{NF}-\kappa \mathrm{B}$ pathway in B lymphomas (30). Leptin enhanced the production of IL- 6 and IL-8 through the activation of NF- $\kappa B$ in OA cartilage (13). In this study, when the cells were transfected with the miR-27 mimic, leptin expression was decreased, thus resulting in the inhibition of $\mathrm{NF}-\kappa \mathrm{B}$, and the downregulation of IL-6, IL-8, MMP-9 and MMP-13. Some miRNAs have been reported to negatively regulate $\mathrm{NF}-\kappa \mathrm{B}$ activation and the production of downstream pro-inflammatory cytokines $(5,31)$. For example, miR-30c-2-3p negatively regulates $\mathrm{NF}-\kappa \mathrm{B}$ signaling, and downregulates IL-8, IL-6 in breast cancer (32). miR-148a has been shown to inhibit NF- $\mathrm{B}$ activation and decrease the expression of ILs and MMPs in the calcification of the aortic valve (33). Our results indicated that miR-27 increased the immunomodulatory activity and inhibited the activation of the NF- $\kappa \mathrm{B}$ pathway by targeting leptin in a rat model of OA.

In conclusion, in the present study, we demonstrate that miR-27 inhibits the progression of OA by targeting leptin. The overexpression of miR-27 exerted anti-inflammatory effects by inhibiting the NF- $\kappa \mathrm{B}$ signaling pathway, suggesting that miR-27 may act as a potential leptin inhibitor for the treatment of OA.

\section{References}

1. Akhtar N, Rasheed Z, Ramamurthy S, Anbazhagan AN, Voss FR and Haqqi TM: MicroRNA-27b regulates the expression of matrix metalloproteinase 13 in human osteoarthritis chondrocytes. Arthritis Rheum 62: 1361-1371, 2010.

2. Vonk LA, Kragten AH, Dhert WJ, Saris DB and Creemers LB: Overexpression of hsa-miR-148a promotes cartilage production and inhibits cartilage degradation by osteoarthritic chondrocytes. Osteoarthritis Cartilage 22: 145-153, 2014.

3. Kerkhof HJ, Bierma-Zeinstra SM, Arden NK, Metrustry S, Castano-Betancourt M, Hart DJ, Hofman A, Rivadeneira F, Oei EH, Spector TD, et al: Prediction model for knee osteoarthritis incidence, including clinical, genetic and biochemical risk factors. Ann Rheum Dis 73: 2116-2121, 2014.
4. Berenbaum F, Eymard F and Houard X: Osteoarthritis, inflammation and obesity. Curr Opin Rheumatol 25: 114-118, 2013.

5. Zhang D, Cao X, Li J and Zhao G: MiR-210 inhibits NF- $\kappa B$ signaling pathway by targeting DR6 in osteoarthritis. Sci Rep 5: 12775, 2015.

6. Marcu KB, Otero M, Olivotto E, Borzí RM and Goldring MB: NF-kappaB signaling: Multiple angles to target OA. Curr Drug Targets 11: 599-613, 2010.

7. Chen LX, Lin L, Wang HJ, Wei XL, Fu X, Zhang JY and Yu CL: Suppression of early experimental osteoarthritis by in vivo delivery of the adenoviral vector-mediated NF-kappaBp65specific siRNA. Osteoarthritis Cartilage 16: 174-184, 2008.

8. Ushita M, Saito T, Ikeda T, Yano F, Higashikawa A, Ogata N Chung U, Nakamura K and Kawaguchi H: Transcriptional induction of SOX9 by NF-kappaB family member RelA in chondrogenic cells. Osteoarthritis Cartilage 17: 1065-1075, 2009.

9. Zhang P, Zhong ZH, Yu HT and Liu B: Significance of increased leptin expression in osteoarthritis patients. PLoS One 10: e0123224, 2015.

10. Bassi M, Furuya WI, Zoccal DB, Menani JV, Colombari E, Hall JE, da Silva AA, do Carmo JM and Colombari DS: Control of respiratory and cardiovascular functions by leptin. Life Sci 125: 25-31, 2015.

11. Wollman L, Powell G, Levine R and Fregosi R: Leptin acutely inhibits respiratory function in neonatal rats (712.18). FASEB J 28 no. 1 Supplement: 712.18, 2014.

12. Bartell SM, Rayalam S, Ambati S, Gaddam DR, Hartzell DL, Hamrick M, She JX, Della-Fera MA and Baile CA: Central (ICV) leptin injection increases bone formation, bone mineral density, muscle mass, serum IGF-1, and the expression of osteogenic genes in leptin-deficient ob/ob mice. J Bone Miner Res 26: 1710$1720,2011$.

13. Vuolteenaho K1, Koskinen A, Kukkonen M, Nieminen R, Päivärinta U, Moilanen T and Moilanen E: Leptin enhances synthesis of proinflammatory mediators in human osteoarthritic cartilage - mediator role of NO in leptin-induced PGE2, IL-6, and IL-8 production. Mediators Inflamm 2009: 345838, 2009.

14. Ku JH, Lee CK, Joo BS, An BM, Choi SH, Wang TH and Cho HL: Correlation of synovial fluid leptin concentrations with the severity of osteoarthritis. Clin Rheumatol 28: 1431-1435, 2009.

15. Honsawek S and Chayanupatkul M: Correlation of plasma and synovial fluid adiponectin with knee osteoarthritis severity. Arch Med Res 41: 593-598, 2010.

16. Li ZC, Han N, Li X, Li G, Liu YZ, Sun GX, Wang Y, Chen GT and Li GF: Decreased expression of microRNA-130a correlates with TNF- $\alpha$ in the development of osteoarthritis. Int J Clin Exp Pathol 8: 2555-2564, 2015.

17. Song J, Jin EH, Kim D, Kim KY, Chun CH and Jin EJ: MicroRNA-222 regulates MMP-13 via targeting HDAC-4 during osteoarthritis pathogenesis. BBA Clin 3: 79-89, 2014.

18. Song J, Kim D, Chun CH and Jin EJ: miR-370 and miR-373 regulate the pathogenesis of osteoarthritis by modulating onecarbon metabolism via SHMT-2 and MECP-2, respectively. Aging Cell 14: 826-837, 2015.

19. Hautier A, Salentey V, Aubert-Foucher E, Bougault C, Beauchef G, Ronzière MC, De Sobarnitsky S, Paumier A, Galéra P, Piperno M, et al: Bone morphogenetic protein-2 stimulates chondrogenic expression in human nasal chondrocytes expanded in vitro. Growth Factors 26: 201-211, 2008.

20. Huang JG, Xia C, Zheng XP, Yi TT, Wang XY, Song G and Zhang B: $17 \beta$-Estradiol promotes cell proliferation in rat osteoarthritis model chondrocytes via PI3K/Akt pathway. Cell Mol Biol Lett 16: 564-575, 2011.

21. Dumond H, Presle N, Terlain B, Mainard D, Loeuille D, Netter P and Pottie P: Evidence for a key role of leptin in osteoarthritis. Arthritis Rheum 48: 3118-3129, 2003.

22. Lee JJ, Drakaki A, Iliopoulos D and Struhl K: MiR-27b targets PPAR $\gamma$ to inhibit growth, tumor progression and the inflammatory response in neuroblastoma cells. Oncogene 31: 3818-3825, 2012.

23. Xu W, Liu M, Peng X, Zhou P, Zhou J, Xu K, Xu H and Jiang S: miR-24-3p and miR-27a-3p promote cell proliferation in glioma cells via cooperative regulation of MXI1. Int J Oncol 42: 757-766, 2013.

24. Urbich C, Kaluza D, Frömel T, Knau A, Bennewitz K, Boon RA, Bonauer A, Doebele C, Boeckel JN, Hergenreider E, et al: MicroRNA-27a/b controls endothelial cell repulsion and angiogenesis by targeting semaphorin 6A. Blood 119: 1607-1616, 2012.

25. Coppari R and Bjørbæk C: Leptin revisited: Its mechanism of action and potential for treating diabetes. Nat Rev Drug Discov 11: 692-708, 2012. 
26. Terlain B, Presle N, Pottie P, Mainard D and Netter P: Leptin: a link between obesity and osteoarthritis? Bull Acad Natl Med 190: 1421-1437, 1475-1477, 2006.

27. Koskinen A, Vuolteenaho K, Nieminen R, Moilanen $\mathrm{T}$ and Moilanen E: Leptin enhances MMP-1, MMP-3 and MMP-13 production in human osteoarthritic cartilage and correlates with MMP-1 and MMP-3 in synovial fluid from OA patients. Clin Exp Rheumatol 29: 57-64, 2011.

28. Mutabaruka MS, Aissa MA, Delalandre A, Lavigne M and Lajeunesse D: Research article Local leptin production in osteoarthritis subchondral osteoblasts may be responsible for their abnormal phenotypic expression. Arthritis Res Ther 12: R20, 2010.

29. Stannus OP, Jones G, Quinn SJ, Cicuttini FM, Dore D and Ding C: Research article the association between leptin, interleukin-6, and hip radiographic osteoarthritis in older people: A cross-sectional study. Arthritis Res Ther 12: R95, 2010.

30. Lam QLK, Wang S, Ko OKH, Kincade PW and Lu L: Leptin signaling maintains B-cell homeostasis via induction of Bcl-2 and Cyclin D1. Proc Natl Acad Sci USA 107: 13812-13817, 2010.
31. Qi J, Qiao Y, Wang P, Li S, Zhao W and Gao C: microRNA-210 negatively regulates LPS-induced production of proinflammatory cytokines by targeting NF- $\kappa \mathrm{B} 1$ in murine macrophages. FEBS Lett 586: 1201-1207, 2012.

32. Shukla K, Sharma AK, Ward A, Will R, Hielscher T, Balwierz A, Breunig C, Münstermann E, König R, Keklikoglou I, et al: MicroRNA-30c-2-3p negatively regulates NF- $\kappa$ B signaling and cell cycle progression through downregulation of TRADD and CCNE1 in breast cancer. Mol Oncol 9: 1106-1119, 2015.

33. Carrion K, Patel V, Dyo J, Holland A, Gallegos T, Hardiman G, Mohamed S, Leire E, Nigam S, Nizet V and Nigam V: miR-148a is a novel repressor of NF- $\mathrm{KB}$ signaling in aortic valve calcification. Circulation 128: A16067, 2013. 